\title{
Phosphorylation of nuclear factor erythroid 2-like 2 (NFE2L2) in mammary tissue of Holstein cows during the periparturient period is associated with mRNA abundance of antioxidant gene networks
}

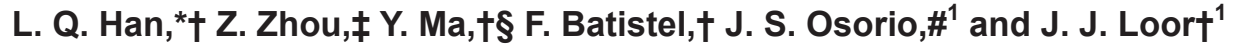 \\ ${ }^{*}$ College of Animal Science and Veterinary Medicine, Henan Agricultural University, Zhengzhou 450002, P. R. China \\ †Mammalian NutriPhysioGenomics, Department of Animal Sciences and Division of Nutritional Sciences, University of Illinois, Urbana 61801 \\ ‡Department of Animal and Veterinary Sciences, Clemson University, 146 Poole Agricultural Center, Clemson, SC 29634 \\ §Institute of Animal Nutrition and Feed, Inner Mongolia Academy of Agriculture and Animal Husbandry Sciences, Hohhot 010031, P. R. China \\ \#Dairy and Food Science Department, South Dakota State University, 1111 College Ave, 113H Alfred Dairy Science Hall, Brookings 57007
}

\begin{abstract}
Changes in the production of reactive oxygen species in the mammary gland of dairy cows during the periparturient period could lead to oxidative stress and potentially impair mammary function. Phosphorylation of the transcription factor nuclear factor erythroid 2-like 2 (NFE2L2), also known as nuclear factor-E2related factor 2, controls mRNA abundance of genes encoding antioxidant proteins and enzymes. The hypothesis was that NFE2L2 phosphorylation status and target gene mRNA abundance in the mammary gland of dairy cows is altered around parturition. Total NFE2L2 protein, phosphorylated protein (p-NFE2L2), and ratio of p-NFE2L2 to NFE2L2 along with mRNA abundance of 24 genes related to the NFE2L2 signaling pathway, apoptosis, and cell proliferation were measured in mammary tissue samples from Holstein cows at $-30,1,15$, and $30 \mathrm{~d}$ relative to parturition. Although total NFE2L2 protein abundance did not differ, p-NFE2L2 and p-NFE2L2-to-NFE2L2 ratio were greater after parturition. The upregulation of DNA damage inducible transcript 3 (DDIT3) postpartum indicated a localized oxidative stress state. Among genes evaluated, thioredoxin $(T X N)$, glutathione peroxidase 1 (GPX1), and glutathione S-transferase mu 1 (GSTM1) had the highest $(37.1,15.1$, and $4.8 \%$ of total mRNA measured, respectively) abundance. The mRNA abundance of various target genes with detoxifying enzymatic functions and free radical scavenging activities [glutamate-cysteine ligase catalytic subunit $(G C L C)$; glutathione reductase $(G S R)$; ferrochelatase (FECH); TXN; thioredoxin reductase 1 (TXNRD1);
\end{abstract}

Received December 7, 2017.

Accepted March 14, 2018.

${ }^{1}$ Corresponding authors: jloor@illinois.edu; johan.osorio@sdstate. edu and $\mathrm{NAD}(\mathrm{P}) \mathrm{H}$ quinone dehydrogenase 1 (NQO1)] were consistently upregulated (linear effect of time) as parturition approached and lactation began. Among the transcription regulators, NFE2L2 had the highest mRNA abundance (7.3\% of total mRNA measured). Abundance of NFE2L2 and other transcription factors [nuclear factor kappa B subunit 1 (NFKB1), retinoid $\mathrm{X}$ receptor $\alpha(R X R A)$, and mitogen-activated protein kinase 14 (MAPK14)] were upregulated (linear effect of time) from $-30 \mathrm{~d}$ to $30 \mathrm{~d}$ relative to parturition. Overall, NFE2L2 phosphorylation and downstream signaling leading to postpartal upregulation of genes associated with oxidative stress and inflammation in the mammary gland seem to be key components of normal cellular function to maintain proper redox homeostasis. However, if the longitudinal increases in mRNA and protein abundance of these antioxidant mechanisms are a reflection of cellular oxidative stress, then the likelihood of protein and DNA damage would be greater and might be one factor compromising cell viability and potentially lactation persistency. The actual cues coordinating these molecular responses remain to be determined.

Key words: oxidative stress, lactation, reactive oxygen metabolites

\section{INTRODUCTION}

Dairy cows experience extreme adaptations in cellular metabolism during the periparturient or transition period as the mammary gland prepares for lactation (Sordillo and Aitken, 2009; Sordillo et al., 2009). At the onset of milk synthesis, tissues such as the liver and mammary gland more than double oxidative metabolism, often leading to increased rates of reactive oxygen species (ROS) production (Aitken et al., 2009). Hence, an imbalance between ROS and antioxidant capacity (Valko et al., 2007) can lead to oxidative stress and onset of pathological conditions associated with 
reproduction, production, and welfare (Lykkesfeldt and Svendsen, 2007).

Evidence from in vitro studies indicates that in lactating mammary epithelial cells metabolic rate is associated with ROS production (Jin et al., 2014), and intracellular antioxidant systems that are controlled via transcriptional mechanisms, such as glutathione metabolism, the thioredoxin system, and heme and Fe metabolism systems, help control redox state. In fact, various types of stressors seem to trigger cellular mechanisms to prevent oxidative stress. For instance, intramammary mastitis challenge at midlactation altered abundance of nuclear factor erythroid 2-like 2 (NFE2L2)-mediated oxidative stress genes (Moyes et al., 2010). Nutritional management also seems to elicit a response by the NFE2L2 pathway, as demonstrated by reductions in oxidative stress indicators in plasma and upregulation of NFE2L2 mRNA abundance in mammary tissue when cows were fed flax meal (Schogor et al., 2013). Jin et al. (2016b) reported that upregulation of NFE2L2 target genes attenuated heat stress-induced cell damage in bovine mammary epithelial cells. Together, these data suggest that NFE2L2 is a key transcription factor for cellular resistance to oxidative stress in the bovine mammary gland. To our knowledge, changes in total protein abundance and phosphorylation status of NFE2L2, along with its target genes in bovine mammary tissue during the periparturient period, are unknown.

The general hypothesis was that NFE2L2 phosphorylation status and mRNA abundance of target genes associated with responses to cellular stress in the mammary gland of dairy cows is altered around parturition. Those data would be indicative of a localized response of the mammary gland to changes in mammary function as a result of lactation, and may be related to protective mechanisms against oxidative damage. To address this hypothesis, we profiled the total protein and phosphorylated protein abundance of NFE2L2 along with mRNA abundance of 24 target genes in mammary tissue harvested at $-30,1,15$, and $30 \mathrm{~d}$ relative to parturition.

\section{MATERIALS AND METHODS}

\section{Animals and Biopsies}

All procedures involving animals were conducted under protocols approved by the University of Illinois Institutional Animal Care and Use Committee. Eight multiparous Holstein dairy cows were used for percutaneous biopsies of the right or left rear quarter of the mammary gland at $-30( \pm 3 \mathrm{~d}), 1,15$, and $30 \mathrm{~d}$ relative to parturition according to previous procedures and with some modifications (Bionaz and Loor, 2007). All biopsies were harvested at approximately $0700 \mathrm{~h}$ (after the morning milking). The midsection of the rear quarters were chosen for biopsy, with each subsequent biopsy located approximately $5 \mathrm{~cm}$ above or below from the original incision site. Before the procedure, cows were given a general anesthetic $(0.025 \mathrm{mg} / \mathrm{kg}$ of xylazine, $20 \mathrm{mg} / \mathrm{mL}$ of solution); before performing the incision, $5 \mathrm{~mL}$ of lidocaine $\mathrm{HCl}$ ( $2 \%$ solution) were given subcutaneously. A 3-cm incision was made through the skin and subcutaneous tissue followed by blunt dissection of connective tissue surrounding the mammary capsule before puncture of the mammary parenchyma. Only after the pink mammary capsule was clearly visible were biopsies performed by first ensuring that the tip of the biopsy needle could go through the dissected connective tissue. Approximately 50 to $100 \mathrm{mg}$ of tissue was removed after 4 punctures (per institutional guidelines) of 5 to $10 \mathrm{~cm}$ in depth using a biopsy needle (Bard Magnum; 12 gauge $\times 16 \mathrm{~cm}$; C. R. Bard, Inc., Murray Hill, NJ). Tissue was blotted with gauze to remove excess blood and any connective tissue. Pressure was then applied to the wound until visual signs of bleeding were absent ( $\sim 5$ min postbiopsy). The skin incision was closed with 3 Michel clips (11 mm; Henry Schein, Melville, NY). The incision site was sprayed with topical antiseptic (10\% Povidone Iodine Ointment; Taro Pharmaceuticals, Hawthorne, NY). Health was monitored after surgery by recording milk yield, rectal temperature, and feed intake daily for $7 \mathrm{~d}$. Surgical clips were removed $7 \mathrm{~d}$ postbiopsy. Cows did not experience clinical signs of disease during the study.

\section{RNA Isolation, cDNA Synthesis, and PCR}

These procedures have been thoroughly described by Bionaz and Loor $(2008,2011)$. Briefly, RNA quality was measured using an Agilent 2100 Bioanalyzer (Agilent, Santa Clara, CA). All samples had an RNA integrity number greater than 7.3. Total RNA was reverse-transcribed using the SuperScript III First Strand Synthesis kit (Thermo Fisher Scientific, Waltham MA). Realtime reverse-transcription PCR (quantitative; qPCR) analysis was performed using SYBR Green Fast Mix ROX (Quanta Biosciences, Gaithersburg, MD) with a 6-point standard curve. A comprehensive literature search (Chorley et al., 2012; Niture and Jaiswal, 2012; Jin et al., 2016a) was conducted to select NFE2L2 target genes and regulators with key roles in the antioxidant mechanisms evaluated (Supplemental Table S1; https://doi.org/10.3186/jds.2017-14257). This included the cell apoptosis regulator $B C L 2$, the glutathione metabolism system (GCLC, GCLM, GPX1, GSR, GSTM1, ME1 and TALDO1), the thioredoxin enzyme 
system (TXNRD1, TXN), the heme and Fe metabolism system (HMOX1, FECH, FTH1, PIR), and NAD (P) H quinone dehydrogenase 1 gene (NQO1), KEAP-dependent regulators (NFE2L2, KEAP1, CUL3) and KEAPindependent regulators (NFKB1, MAPK8, MAPK12, $M A P K 14, R X R A)$. Gene symbols, primer features, and qPCR performance are reported in Supplemental Table S2 (https://doi.org/10.3186/jds.2017-14257).

\section{Relative mRNA Abundance of Transcripts}

These procedures have been described in detail elsewhere (Bionaz and Loor, 2007, 2008, 2011). Briefly, RT-PCR was performed using $4 \mu \mathrm{L}$ of diluted cDNA combined with $6 \mu \mathrm{L}$ of a mixture composed of $5 \mu \mathrm{L}$ of 1 SYBR Green master mix (Quanta Biosciences), $0.4 \mu \mathrm{L}$ each of $10 \mu M$ forward and reverse primers, and $0.2 \mu \mathrm{L}$ of DNase/RNase free water in a MicroAmp Optical 384Well Reaction Plate (Applied Biosystems, Foster City, CA). Each sample was run in triplicate and a 6-point standard curve (a pool from cDNA of all samples) plus the nontemplate control were used. The reactions were performed in an ABI Prism 7900 HT SDS instrument (Applied Biosystems). The mRNA abundance for each gene was calculated relative to the 6-point standard curve with the 7900 HT Sequence Detection Systems Software (version 2.2.1, Applied Biosystems). The overall percentage mRNA abundance for each gene among all those measured was calculated using the inverse of PCR efficiency (E) raised to $\Delta \mathrm{Ct}$ [gene abundance 1/E Median $\Delta \mathrm{Ct}$, where the median of $\Delta \mathrm{Ct}$ is calculated as (cycle threshold of the target gene - geometrical mean cycle threshold of 3 internal controls) for each time point]. The efficiency of PCR amplification for each gene was calculated using the standard curve method $\left[\mathrm{E} 10^{(-1 / \text { standard curve slope })}\right]$ as described in various manuscripts from our laboratory (Bionaz and Loor, 2007, $2008,2011)$. The final data were normalized using the geometric mean of UXT, RPS9, and RPS15 (Bionaz and Loor, 2007).

\section{Western Blot Analysis}

Total protein was extracted from mammary gland tissue using T-PER tissue protein extraction reagent (catalog number: 78510; Thermo Fisher Scientific) including a protease and phosphatase inhibitor cocktail (catalog number 78440; Thermo Fisher Scientific). The concentrations of total protein was determined with the Pierce BCA protein assay kit (catalog number 23227; Thermo Fisher Scientific). After protein samples were boiled at $100^{\circ} \mathrm{C}$ for $10 \mathrm{~min}, 50 \mu \mathrm{g}$ of protein was loaded into wells of a $10 \%$ SDS-PAGE gel and run at $120 \mathrm{~V}$ for $120 \mathrm{~min}$. After activating a polyvinyldene fluoride membrane (catalog number 1620261; Bio-Rad, Hercules, CA) with methanol for $1 \mathrm{~min}$, the protein sample was transferred to the membrane using a semidry transfer assembly (Bio-Rad). Membranes were blocked for $2 \mathrm{~h}$ at room temperature using TBST (50 $\mathrm{m} M$ Tris, $\mathrm{pH}$ 7.6, $150 \mathrm{mM} \mathrm{NaCl}$, and $0.1 \%$ Tween 20) containing $5 \%$ (wt/vol) nonfat milk. The membranes were then washed 5 times and incubated with TBST containing antibodies to NFE2L2 (catalog number137550; Abcam, Cambridge, UK) and Phospho-NFE2L2 (catalog numberPA5-67520; Invitrogen, Carlsbad, CA) with gentle agitation at $4^{\circ} \mathrm{C}$ overnight. Subsequently, the membranes were washed 5 times with TBST, 5 min each time at room temperature. After incubated with horseradish peroxide-conjugated secondary antibodies (catalog number ab6721; Abcam) at room temperature for $1 \mathrm{~h}$, anti-GAPDH antibody (catalog number ab22555; Abcam) was used as internal control. The membranes were incubated with Clarity ECL Western blotting substrate (catalog number 170-5060; Bio-Rad) and images were captured using a ChemiDOC MP system (Bio-Rad). The intensity of the bands were measured using Image-Pro Plus 6.0 software (Media Cybernetics Inc., Rockville, MD).

\section{Statistical Analysis}

Normalized qPCR data for DDIT3, GCLC, and $K E A P 1$ had to be log-2 transformed before statistical analysis because the Shapiro-Wilk test $P$-value was $<0.05$. Subsequently, statistical analysis on all mRNA data was performed using repeated measures ANOVA with the MIXED procedure of SAS 9.3 (SAS Institute Inc., Cary, NC) to evaluate the effect of time relative to parturition. The model included the fixed effect of time $(-30,1,15$, and $30 \mathrm{~d})$ and the random effect of cow. Orthogonal polynomial contrasts were used to evaluate linear and quadratic effects of time on protein and mRNA abundance. Significance was declared at a corrected $P \leq 0.05$. Data for DDIT3, GCLC, and $K E A P 1$ in Figures are the back-transformed least squares means.

\section{RESULTS}

\section{Total NFE2L2 Protein Abundance and Phosphorylation Status}

Although total protein abundance did not differ $(P=$ 0.18 ) at $30 \mathrm{~d}$ postpartum relative to $-30 \mathrm{~d}$ (Figure 1 ), the abundance of phosphorylated (p) NFE2L2 tended $(P=0.09)$ to increase and the p-NFE2L2-to-total NFE2L2 ratio increased $(P=0.05)$ after calving. 
HAN ET AL.

Table 1. Relative percentage mRNA abundance of target genes measured

\begin{tabular}{llc}
\hline Gene name & Symbol $^{1}$ & RNA $^{2}(\%)$ \\
\hline DNA damage inducible transcript 3 & DDIT3 & $<0.01$ \\
BCL2 apoptosis regulator & BCL2 & 1.09 \\
Glutathione reductase & GSR & 0.91 \\
Glutamate-cysteine ligase catalytic subunit & GCLC & 1.38 \\
Glutathione peroxidase 1 & GPX1 & 15.1 \\
Glutamate-cysteine ligase modifier subunit & GCLM & 1.43 \\
Glutathione S-transferase M1 & GSTM1 & 4.78 \\
Malic enzyme 1 & ME1 & 0.73 \\
Transaldolase 1 & TALDO1 & 0.38 \\
Thioredoxin & TXN & 37.0 \\
Thioredoxin reductase 1 & TXNRD1 & 3.36 \\
Ferrochelatase & FECH & 0.72 \\
Heme oxygenase 1 & HMOX1 & 3.99 \\
Ferritin heavy chain 1 & FTH1 & 4.01 \\
Pirin (iron-binding nuclear protein) & PIR & 1.23 \\
NAD(P)H quinone dehydrogenase 1 & NQO1 & 0.47 \\
Nuclear factor, erythroid 2-like 2 & NFE2L2 & 7.32 \\
Kelch-like ECH-associated protein 1 & KEAP1 & 3.06 \\
Cullin 3 & CUL3 & 4.26 \\
Nuclear factor kappa B subunit 1 & NFKB1 \\
Mitogen-activated protein kinase 12 & MAPK12 \\
Mitogen-activated protein kinase 14 & MAPK14 & 3.25 \\
Mitogen-activated protein kinase 8 & MAPK8 & 0.72 \\
Retinoid X receptor $\alpha$ & RXRA & 1.34 \\
\hline
\end{tabular}

${ }^{1}$ From National Center for Biotechnology Information (NCBI; https://www.ncbi.nlm.nih.gov/).

${ }^{2}$ Calculated as $[(1 / \mathrm{E} \Delta \mathrm{Ct})$ specific gene/sum $(1 / \mathrm{E} \Delta \mathrm{Ct})$ all genes $] \times 100$, where $\mathrm{E}=$ efficiency and $\Delta \mathrm{Ct}=$ median of $\Delta$ cycle threshold (calculated as cycle threshold of the target gene minus geometrical mean cycle threshold of 3 internal controls).

\section{Oxidative Stress and NFE2L2 Target Gene Abundance}

Among the measured NFE2L2 target genes, TXN, GPX1, and GSTM1 had the highest percentage mRNA abundance (Table 1). Compared with $-30 \mathrm{~d}$, abundance of GPX1 and GSTM1 increased at $30 \mathrm{~d}$ (linear and quadratic effect, $P<0.05$; Figure 2). Abundance of the thioredoxin enzyme system (TXN and TXNRD1) increased gradually during early lactation with a linear pattern $(P<0.05$, Figure 2$)$. The antioxidant enzyme genes measured in the glutathione metabolism system (GSR, GCLC, ME1, and TALDO1) decreased at $1 \mathrm{~d}$ and then peaked in mRNA abundance at 15 or $30 \mathrm{~d}$ postpartum (linear effect, $P<0.05$, Figure 2).

In the heme and Fe metabolism system, percentage mRNA abundance of FECH and PIR was low $(<1.5 \%$ of total mRNA; Table 1), but both genes experienced a linear increase in abundance after parturition compared with $-30 \mathrm{~d}(P<0.05$, Figure 3$)$. The abundance of HMOX1 and FTH1 was not affected over time $(P>$ 0.09; Figure 3).

Although not among the most abundant genes on a percentage basis, the abundance over time of DDIT3 increased linearly from -30 to $30 \mathrm{~d}$ relative to parturition $(P<0.01$, Figure 4$)$. Compared with $-30 \mathrm{~d}$, abundance of BCL2 increased at $1 \mathrm{~d}$ and peaked at 30 d postpartum (linear and quadratic effect, $P<0.05$ ); this gene accounted for $\sim 1 \%$ of total mRNA abundance measured (Figure 4). Compared with $-30 \mathrm{~d}$, NQO1 abundance was downregulated (linear effect, $P<0.05$ )

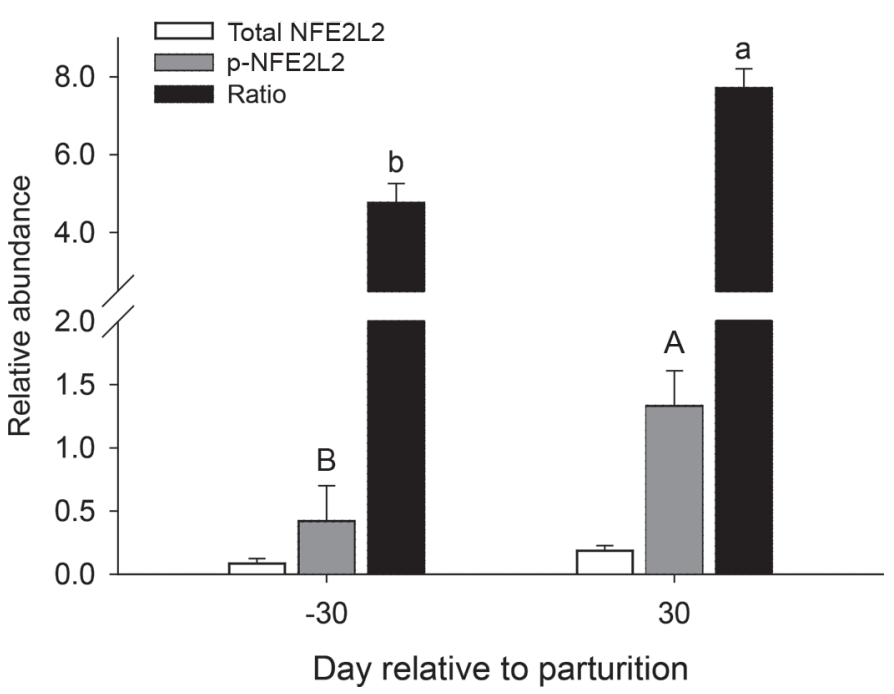

Figure 1. Abundance of total NFE2L2, phosphorylated NFE2L2 (p-NFE2L2), and the ratio of p-NFE2L2 to total NFE2L2 protein in mammary gland tissue of multiparous Holstein dairy cows during the periparturient period. Different lowercase letters $(a, b)$ indicate means differ $(P<0.05)$; different uppercase letters (A.B) indicate means tend to differ $(P=0.09)$. Error bars represent the SEM. 

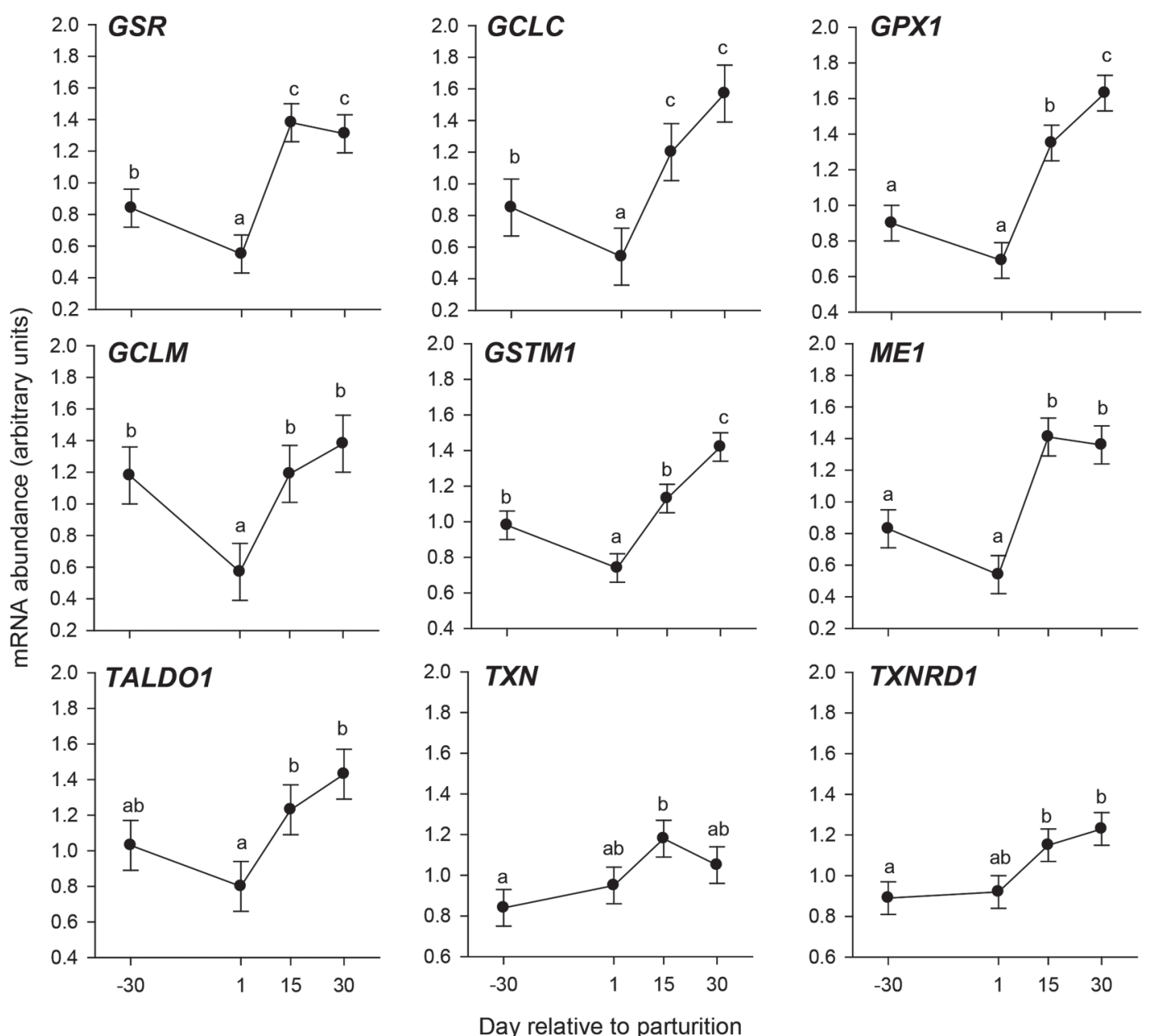

Figure 2. Abundance of mRNA for genes associated with glutathione metabolism (GSR, GCLC, GPX1, GCLM, GSTM1, ME1, and $T A L D O 1)$ and the thioredoxin pathway (TXN, TXNDR1). GSR = glutathione reductase; $G C L C=$ glutamate-cysteine ligase catalytic subunit; GPX1 = glutathione peroxidase; $G C L M=$ glutamate-cysteine ligase modifier subunit; $G S T M 1=$ glutathione S-transferase M1; $M E 1=$ malic enzyme 1; TALDO1 = transaldolase $1 ; T X N=$ thioredoxin; TXNDR1 = thioredoxin reductase 1 . Different letters (a-c) indicate means differ $(P \leq 0.05)$. Error bars represent the SEM.

at $1 \mathrm{~d}$ and then upregulated at $15 \mathrm{~d}$ before reaching peak expression at $30 \mathrm{~d}$ (Figure 4).

\section{NFE2L2 Regulator Genes}

Among the measured regulators of NFE2L2, KEAPdependent regulators (NFE2L2, CUL3, and KEAP1) had the highest mRNA abundance (Table 1), accounting for 4 to $7 \%$ of total mRNA abundance measured. The mRNA abundance of NFE2L2 was lowest at $1 \mathrm{~d}$ and then reached highest abundance at $30 \mathrm{~d}$ (linear effect, $P<0.05$; Figure 5). The abundance of KEAP1 decreased at $1 \mathrm{~d}$ postpartum, and then had a linear increase at 15 and $30 \mathrm{~d}$, where it peaked relative to -30 d (Figure 5). The abundance of NFKB1, MAPK14, and $R X R A$ was greater at 30 compared with $-30 \mathrm{~d}$ (linear effect of time, $P<0.05$; Figure 5 ). No changes in abun- dance of $M A P K 8$ and $C U L 3$ around parturition were observed $(P>0.10$, Figure 5$)$.

\section{DISCUSSION}

Although multiple biopsies of the same tissue could potentially confound the interpretation of mRNA and protein abundance data, it is unlikely that the procedure used in the present study had an effect on the biologic processes of interest. First, biopsies alternated between the rear quarters such that the same quarter was not biopsied for a period of weeks. Second, a different location was biopsied each time, ensuring that scar tissue was avoided. Lastly, in previous work from our group performing similar experiments (Bionaz and Loor, 2012), at least from the metabolic standpoint, we have been able to capture the expected temporal 


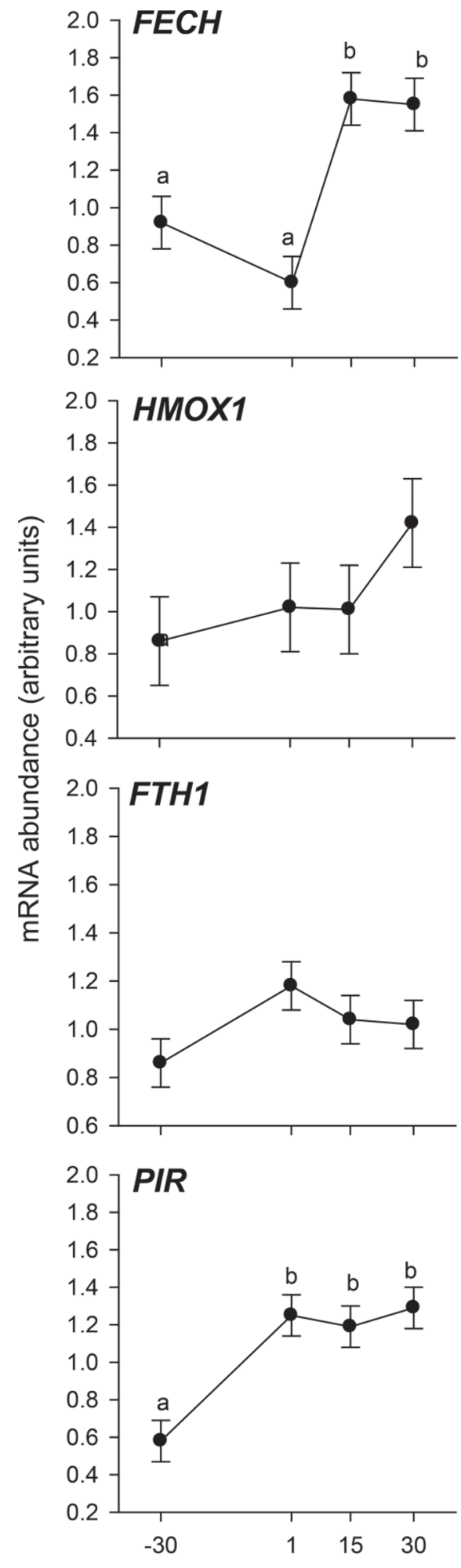

Day relative to parturition

Figure 3. Abundance of mRNA for genes associated with heme and iron metabolism. $F E C H=$ ferrochelatase; $H M O X 1=$ heme oxygenase 1; FTH1 = ferritin heavy chain $1 ; P I R=$ pirin (iron-binding nuclear protein. Different letters $(\mathrm{a}, \mathrm{b})$ indicate means differ $(P \leq 0.05)$. Error bars represent the SEM.
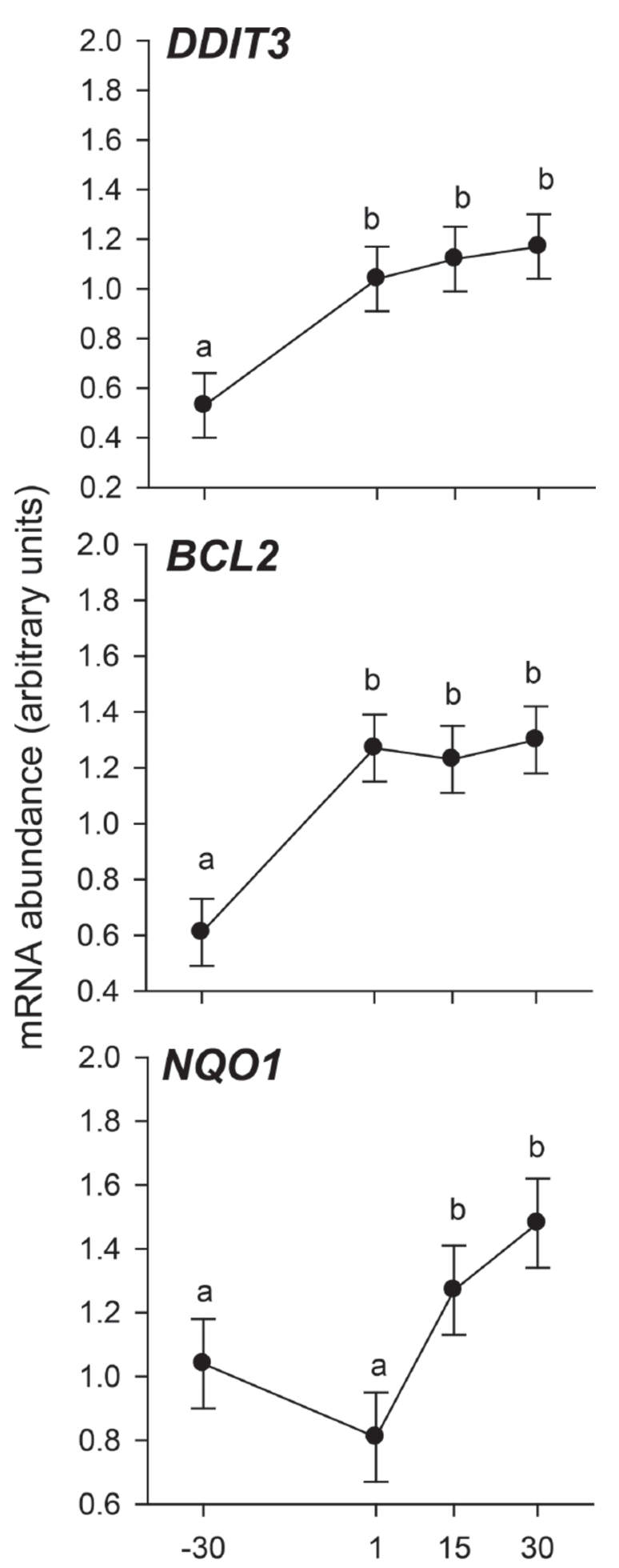

\section{Day relative to parturition}

Figure 4. Abundance of mRNA for genes associated with apoptosis (DDIT3), cell proliferation (BCL2), and electron reduction (NQO1). DDIT3 = DNA damage inducible transcript 3; BCL2 = BCL2 apoptosis regulator; $N Q O 1=\mathrm{NAD}(\mathrm{P}) \mathrm{H}$ quinone dehydrogenase 1 . Different letters $(\mathrm{a}, \mathrm{b})$ indicate means differ $(P \leq 0.05)$. Error bars represent the SEM. 
biologic response of the mammary gland (e.g., increase in lipogenesis; Mellenberger et al., 1973). The fact that repeated biopsies of liver during a 48 -h period in lactating Holstein cows had minimal effects on mRNA abundance and systemic indicators of inflammation and stress also support the applicability of this type of procedure (Vels et al., 2009).

The onset of lactation is characterized not only by metabolic and endocrine changes, but also by changes in immune and oxidative stress status (Everts et al., 2005; Loor et al., 2013). These multifaceted adaptations are partly driven by the increased demands for nutrients in the mammary gland that are needed to support milk component synthesis. The sudden increase in metabolic activity of tissues at the onset of lactation is a well-coordinated process that ensures proper nutrient supply to mammary gland, but indirectly results in the production of ROS (Sordillo and Aitken,
2009; Sordillo et al., 2009). In fact, systemic biomarker analysis has demonstrated that dairy cows experience oxidative stress throughout the transition period, and particularly after parturition (Bertoni et al., 2008). When produced in excess or in a chronic fashion and without proper antioxidant mechanisms, ROS can lead to oxidative stress and harm cells that could result in loss of function and tissue damage (e.g., cell apoptosis; Young and Woodside, 2001). Because the abundance of DDIT3 mRNA and cellular apoptosis is increased by hydrogen peroxide (Ariyama et al., 2008) and ROSinduced oxidative stress (Feng et al., 2014), the gradual increase in DDIT3 expression after calving in the present study suggests some degree of oxidative stress in mammary gland. Alternatively, the profile of DDIT3 may represent a normal response in cellular apoptosis, which in a previous study was reported to be highest at 14 d postpartum (Capuco et al., 2001).
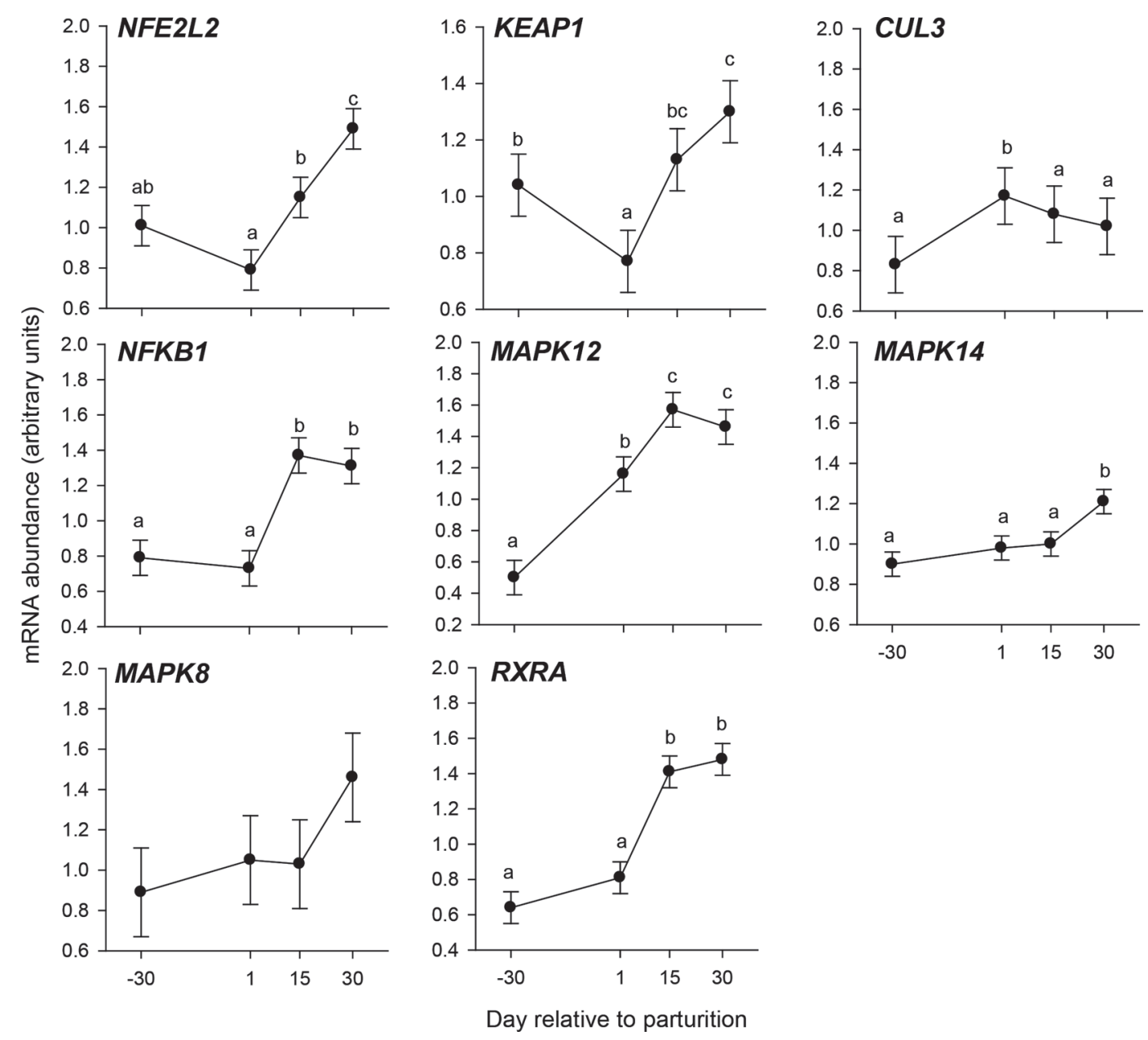

Figure 5. Abundance of mRNA for genes associated with redox-sensitive regulation of nuclear factor, erythroid 2-like 2 (NFE2L2) action. Kelch-like ECH associated protein 1 (KEAP1)-dependent regulators: NFE2L2, KEAP1; CUL3 = cullin 3. KEAP1-independent regulators: $M A P K 8=$ mitogen-activated protein kinase $8 ; M A P K 12=$ mitogen-activated protein kinase $12 ; M A P K 14=$ mitogen-activated protein kinase 14; $R X R A=$ retinoid $\mathrm{X}$ receptor $\alpha$. Different letters $(\mathrm{a}-\mathrm{c})$ indicate means differ $(P \leq 0.05)$. Error bars represent the SEM. 


\section{KEAP-Dependent NFE2L2 Regulators}

Under oxidative stress conditions, at least in nonruminants, the active form of NFE2L2 translocates to the nucleus, where it can upregulate its target genes by binding to the antioxidant response element, ultimately triggering molecular events that help reduce ROS levels (Menegon et al., 2016). The stability of NFE2L2 protein is primarily regulated by Kelch-like ECH-associated protein 1 (KEAP1), which forms a homodimer to inactivate NFE2L2 in the cytosol. In addition, KEAP1 facilitates CUL3-dependent NFE2L2 ubiquitination, leading to its proteasomal degradation (Hine and Mitchell, 2012). Although, to our knowledge, in vivo data in bovine mammary tissue are not available, research with bovine embryos underscored the importance of KEAP1 and NFE2L2 interactions in the context of controlling endogenous antioxidant mechanisms during oxidative stress conditions (Amin et al., 2014). If such a mechanism also functions in mammary tissue, it would partly explain the similar pattern of increase in postpartum abundance of NFE2L2 and KEAP1.

Previous research with bovine mammary tissue or mammary cells has reported changes in mRNA abundance of NFE2L2 in response to LPS or has associated its expression with oxidative status. For instance, greater NFE2L2 mRNA abundance in mammary tissue was accompanied with improved oxidative status in midlactation Holstein cows (Schogor et al., 2013). In bovine mammary cells, LPS downregulated the abundance of NFE2L2 mRNA (Yu et al., 2017). A cytoprotective effect of NFE2L2 upregulation in MAC-T cells during heat shock when incubating with the antioxidant tertbutylhydroquinone was due in part to upregulation of NFE2L2 target genes (Jin et al., 2016b). Therefore, the finding that KEAP-dependent regulators had the third highest mRNA abundance among the genes evaluated underscores their importance in bovine mammary tissue around parturition. This idea is further substantiated by the increase in the ratio of p-NFE2L2 to total NFE2L2 after calving and the fact that the profile of NFE2L2 mRNA abundance was similar to that of genes related to antioxidant enzymes.

In nonruminants, several studies have pointed toward stress-induced phosphorylation of NFE2L2 and its nuclear translocation followed by activation of gene expression (Bloom and Jaiswal, 2003; Jaiswal, 2004; Huang et al., 2015). In the present study, the increased ratio of p-NFE2L2 to total NFE2L2 and target gene abundance (e.g., GSR, GCLC, NQO1) after calving suggest that NFE2L2, as a transcription factor, plays a key role in the antioxidant mechanisms of the mammary cell during a period where the animal may experience a chronic state of excessive ROS production. These mechanisms might be one of the physiologic means to prevent tissue damage as a result of ROS production.

\section{KEAP-Independent Regulators}

Although the regulation of NFE2L2 is mainly via KEAP, a body of evidence exists suggesting that NFE2L2 can be positively or negatively regulated by other proteins (Bryan et al., 2013), such as the inflammation-related transcription factor nuclear factor-KB (NFKB) and retinoic X receptor $\alpha$ (RXRA). For instance, an antagonistic relationship exists between the NFE2L2 and NFKB pathway in nonruminant cells (Cuadrado et al., 2014), leading to changes in mRNA abundance of their respective target genes (Wakabayashi et al., 2010). Although no data are available for mammary tissue, midlactation cows undergoing inflammation as a result of feeding a high-grain diet had lower NFE2L2 mRNA abundance and greater NFKB abundance in liver tissue (Abaker et al., 2017). Retinoic $\mathrm{X}$ receptor $\alpha$, a nuclear retinoic acid receptor, regulates nuclear hormone signaling through forming a heterodimer with other nuclear receptors (Xu et al., 1999) and was recently shown to inhibit NFE2L2 (Wu et al., 2014) activity through a protein-protein interaction (Wang et al., 2013). Therefore, considering the upregulation in postpartal abundance of NFKB1 and $R X R A$ along with their relatively high percentage mRNA in the present study, it seems plausible that these transcription regulators exert some degree of control (i.e., as co-repressors) on NFE2L2 and its target genes. However, the marked increase in p-NFE2L2 abundance after parturition seems to underscore its activation as a dominant mechanism during a time when mammary metabolism is at its peak.

The first signaling pathway known to influence NFE2L2 activity was the mitogen-activated protein kinase (MAPK) cascade (Kwak et al., 2004). In fact, the NFE2L2 protein contains several threonine, tyrosine, and serine residues, which can be phosphorylated by various kinases. The MAPK pathway, including extracellular signal-regulated kinase (ERK), c-Jun N-terminal kinase $(\mathbf{J N K})$, and p38 kinase, could all regulate NFE2L2 (Sun et al., 2009). In general, at least in nonruminants, the activation of c-Jun N-terminal kinase and ERK activates NFE2L2, whereas p38 is inhibitory (Huang et al., 2015). Using cultured bovine mammary cells (MAC-T), Jin et al. (2016a) reported that inhibiting p38 kinase enhanced the expression of NFE2L2 and several antioxidant genes. In addition, ERK activation was associated with NFE2L2-mediated activation of antioxidant enzymes (Zipper and Mulcahy, 2003). Similar to NFKB1 and RXRA, the gradual 
increase in mRNA abundance of MAPK12 (ERK) and $M A P K 14$ (p38) likely underscores their participation in a regulatory mechanism that helps control NFE2L2 activity.

\section{NFE2L2 Target Genes}

Regulation of cell death by inducing or inhibiting apoptosis is one of the main roles of $B C L 2$ (Siddiqui et al., 2015), and it has been demonstrated that its promoter region contains an antioxidant response element to which NFE2L2 can bind and activate (Niture and Jaiswal, 2012). In fact, NFE2L2-mediated upregulation of $B C L 2$ enhanced cell survival and drug resistance in cancer cells (Niture and Jaiswal, 2012). Work in murine mammary gland also indicated that BCL2 can inhibit apoptosis (Metcalfe et al., 1999) and extend lactation by promoting survival of mammary epithelial cells (Schorr et al., 1999). In bovine mammary gland tissue, an increase in the proliferation-to-apoptotic cell ratio was associated with a sustained expression of anti-apoptotic BCL2 (Colitti et al., 2004). Therefore, the gradual upregulation of $B C L 2$ postpartum that was detected suggests a role for $B C L 2$ in modulating mammary epithelial cell survival during the transition period.

The first enzyme of GSH biosynthesis that catalyzes the reaction between glutamate and cysteine to form $\gamma$-glutamyl-L-cysteine is glutamate cysteine ligase $(G C L)$, which is composed of catalytic $(G C L C)$ and modifier (GCLM) subunits (Lu, 2013). Glutathione exists in its reduced or oxidized form (i.e., GSH or GSSG, respectively), with reduced GSH playing important functions including antioxidant defense, detoxification, and maintenance of thiol status, which could scavenge ROS (Lu, 2009). Our previous work demonstrated a reduction in liver and plasma GSH concentration from prepartum to early postpartum, followed by a gradual increase through 30 d postpartum (Zhou et al., 2017; Batistel et al., 2018). Pathological conditions are known to affect GSH concentration in milk, and this compound is considered an oxidative stress biomarker (Talukder et al., 2015; Sadek et al., 2017).

At least in nonruminants, oxidative stress is associated with increased concentration of cellular GSH and upregulation of GCL mRNA abundance (Yamane et al., 1998; Huang et al., 2001). Therefore, the postpartal upregulation of $G C L C$ detected in the present study underscores the importance of this subunit during early lactation and within the context of GSH biosynthesis. Alternately, the nadir in mRNA abundance of GCLM at $1 \mathrm{~d}$ postpartum could be related to an acute oxidative stress status shortly after calving.
In the present study, GPX1 and GSTM1 were the second and fourth most abundant transcripts (15 and $4.7 \%$, respectively) among all genes evaluated, suggesting a major role in glutathione metabolism. The upregulation of GPX1 mRNA abundance after parturition is consistent with a previous study (Aitken et al., 2009) and underscores the importance of the GPX enzyme system and its use of GSH to neutralize harmful peroxides and ROS. Another important component of the GSH system is the enzyme GSTM1, which catalyzes the conjugation of GSH to xenobiotic substrates for the purpose of detoxification ( $\mathrm{Lu}, 2013)$. In bovine mammary cells, CLA isomers increased GPX and GSTM activity, enhancing cell resistance against $\mathrm{H}_{2} \mathrm{O}_{2}$-induced oxidative stress (Basiricò et al., 2015). Therefore, the upregulated abundance of GPX1 and GSTM1 after parturition suggests a gradual increase of free radical scavenging and detoxification capacity in the mammary gland postpartum and seems to underscore the importance of NFE2L2 phosphorylation status in the control of this process.

Oxidative stress depends not only on the production of ROS, but also on the level of NADPH and GSH during electron transport in organelles (Perl et al., 2011). The conversion of $\mathrm{NADP}^{+}$to NADPH during the oxidative decarboxylation of (S)-malate to pyruvate via malic enzyme $1(M E 1)$ and the activity of transaldolase 1 (TALDO1) link glycolysis, pentose phosphate, and citric acid pathways in mammary cells (Gumaa et al., 1973). In NFE2L2-KO mice, ME1 was significantly downregulated and was identified as an NFE2L2-regulated gene (Chartoumpekis et al., 2013); TALDO1-deficient liver is characterized by NADPH and GSH depletion along with oxidative stress (Hanczko et al., 2009). Although in ruminant mammary glands the major source of NADPH is the isocitrate dehydrogenase pathway, in nonruminants ME1 is a major source of NADPH (Gumaa et al., 1973). In addition to ME1, TALDO1 activity as part of the pentose phosphate pathway and helps generate NADPH and ribose-5-phosphate for nucleic acid synthesis in mammary cells (Gumaa et al., 1973). Therefore, ME1 and TALDO1 may not be directly involved in the removal of ROS, but rather through the metabolism of NADPH and GSH through their active participation in the antioxidant mechanism of glutathione. Overall, the upregulation in abundance of the glutathione metabolism enzymes suggest this system may play a key role in the control of oxidative stress in mammary cells.

The activity of thioredoxin reductase1 (TXNRD1) and availability of thioredoxin (TXN) constitute a powerful oxidoreductase system with important antioxidant effects (Nordberg and Arner, 2001). The thio- 
redoxin system reduces disulfide bridges of proteins and removes peroxides or $\mathrm{H}_{2} \mathrm{O}_{2}$ by using NADPH as an electron donor ( $\mathrm{Lu}$ and Holmgren, 2014). The TXNRD1 is the only enzyme that catalyzes the transfer of electrons to the active site of TXN, which continues to reduce protein disulfide bridges or other substrates (Du et al., 2013). The importance of this gene or protein in bovine mammary tissue clearly is underscored by the fact it had the greatest mRNA abundance (37\% of all mRNA measured) among all genes evaluated. The gradual increase in TXNRD1 abundance over time suggested this was a sustained mechanism potentially dedicated to removing ROS via TXN. Our data are in agreement with a previous study reporting that TXNRD1 activity in blood is an important antioxidant defense mechanism during the transition period in dairy cows (Gong and Xiao, 2016).

Hemeoxygenase- 1 catalyzes the breakdown of heme to carbon monoxide, biliverdin, and iron (Wegiel et al., 2014). When Fe is rapidly lost from the hemoglobin porphyrin ring, free heme can cause oxidative damage and contribute to the ferrous state producing ROS. Free iron is stored by ferritin1, whereas ferrochelatase catalyzes the biosynthesis of heme (Kim et al., 2014). Pirin is an Fe(II)-binding nuclear protein that belongs to the redox-sensitive cupin superfamily. The upregulation in abundance of FECH after calving is in agreement with previous data in dairy cows (Wang et al., 2015). Free iron is toxic to cells, as it acts as a catalyst and leads to tissue damage derived from free radical toxicity via the Fenton reaction (Jomova and Valko, 2011). Therefore, the increase in FECH and PIR after calving suggest a response of mammary cells to stress conditions potentially caused by $\mathrm{Fe}^{2+}$.

By using NADPH as the hydrogen donor, NQO1 catalyzes the reduction of a broad array of quinones to their corresponding hydroquinones, hence this protein prevents the 1-electron reduction of quinones that results in ROS production (Dinkova-Kostova et al., 2004; Dinkova-Kostova and Talalay, 2010). In addition to its catalytic role as an antioxidant enzyme in the reduction of quinines (Glorieux et al., 2016), NQO1 has been reported to protect against estrogen quinone-mediated DNA and protein damage in human mammary epithelial cells (Yang et al., 2013). Similar to the observed postpartal upregulation of NQO1 in mammary tissue, it was reported that $N Q O 1$ was upregulated in the liver of dairy cows during the transition period (Gessner et al., 2013). Because both liver and mammary tissue undergo a significant degree of oxidative stress postpartum (Wang et al., 2012), it is conceivable that NQO1 plays a protective role against oxidative stress.

\section{CONCLUSIONS}

The increase in phosphorylation status of the NFE2L2 transcription regulator during the postpartum period appears to be one mechanism that helps coordinate the upregulation of mRNA abundance of various antioxidant target genes. Although the present study did not specifically examine oxidative stress status, ROS production, or antioxidant capacity of mammary tissue, the data suggest that signaling through the NFE2L2 pathway is a key component of normal cellular function to maintain proper redox homeostasis. However, if the longitudinal increases in mRNA and protein abundance of these antioxidant mechanisms are a reflection of cellular oxidative stress, then the likelihood of protein and DNA damage would be greater and might be one factor compromising cell viability and potentially lactation persistency.

\section{ACKNOWLEDGMENTS}

L. Q. Han and Y. Ma were recipients of postdoctoral fellowships from China Scholarship Council (Beijing) to train at the University of Illinois (Urbana). The research was supported in part by Hatch funds under project ILLU-538-914, National Institute of Food and Agriculture (Washington, DC).

\section{REFERENCES}

Abaker, J. A., T. L. Xu, D. Jin, G. J. Chang, K. Zhang, and X. Z. Shen. 2017. Lipopolysaccharide derived from the digestive tract provokes oxidative stress in the liver of dairy cows fed a high-grain diet. J. Dairy Sci. 100:666-678. https://doi.org/10.3168/jds.2016 -10871 .

Aitken, S. L., E. L. Karcher, P. Rezamand, J. C. Gandy, M. J. VandeHaar, A. V. Capuco, and L. M. Sordillo. 2009. Evaluation of antioxidant and proinflammatory gene expression in bovine mammary tissue during the periparturient period. J. Dairy Sci. 92:589-598. https://doi.org/10.3168/jds.2008-1551.

Amin, A., A. Gad, D. Salilew-Wondim, S. Prastowo, E. Held, M. Hoelker, F. Rings, E. Tholen, C. Neuhoff, C. Looft, K. Schellander, and D. Tesfaye. 2014. Bovine embryo survival under oxidativestress conditions is associated with activity of the NRF2-mediated oxidative-stress-response pathway. Mol. Reprod. Dev. 81:497-513.

Ariyama, Y., Y. Tanaka, H. Shimizu, K. Shimomura, S. Okada, T. Saito, E. Yamada, S. Oyadomari, M. Mori, and M. Mori. 2008. The role of CHOP messenger RNA expression in the link between oxidative stress and apoptosis. Metabolism 57:1625-1635. https:// doi.org/10.1016/j.metabol.2008.06.019.

Basiricò, L., P. Morera, D. Dipasquale, A. Troscher, A. Serra, M. Mele, and U. Bernabucci. 2015. Conjugated linoleic acid isomers strongly improve the redox status of bovine mammary epithelial cells (BME-UV1). J. Dairy Sci. 98:7071-7082. https://doi.org/10 .3168/jds.2015-9787.

Batistel, F., J. M. Arroyo, C. I. M. Garces, E. Trevisi, C. Parys, M. A. Ballou, F. C. Cardoso, and J. J. Loor. 2018. Ethyl-cellulose rumen-protected methionine alleviates inflammation and oxidative stress and improves neutrophil function during the periparturient 
period and early lactation in Holstein dairy cows. J. Dairy Sci. 101:480-490. https://doi.org/10.3168/jds.2017-13185.

Bertoni, G., E. Trevisi, X. Han, and M. Bionaz. 2008. Effects of inflammatory conditions on liver activity in puerperium period and consequences for performance in dairy cows. J. Dairy Sci. 91:33003310. https://doi.org/10.3168/jds.2008-0995.

Bionaz, M., and J. J. Loor. 2007. Identification of reference genes for quantitative real-time PCR in the bovine mammary gland during the lactation cycle. Physiol. Genomics 29:312-319.

Bionaz, M., and J. J. Loor. 2008. Gene networks driving bovine milk fat synthesis during the lactation cycle. BMC Genomics 9:366. https://doi.org/10.1186/1471-2164-9-366.

Bionaz, M., and J. J. Loor. 2011. Gene networks driving bovine mammary protein synthesis during the lactation cycle. Bioinform. Biol. Insights 5:83-98. https://doi.org/10.4137/BBI.S7003.

Bionaz, M., and J. J. Loor. 2012. Old and new stories: Revelations from functional analysis of the bovine mammary transcriptome during the lactation cycle. PLoS One 7:e33268. https://doi.org/10 .1371/journal.pone.0033268.

Bloom, D. A., and A. K. Jaiswal. 2003. Phosphorylation of Nrf2 at Ser40 by protein kinase $\mathrm{C}$ in response to antioxidants leads to the release of Nrf2 from INrf2, but is not required for Nrf2 stabilization/accumulation in the nucleus and transcriptional activation of antioxidant response element-mediated NAD $(\mathrm{P}) \mathrm{H}$ :quinone oxidoreductase-1 gene expression. J. Biol. Chem. 278:44675-44682.

Bryan, H. K., A. Olayanju, C. E. Goldring, and B. K. Park. 2013. The Nrf2 cell defence pathway: Keap1-dependent and -independent mechanisms of regulation. Biochem. Pharmacol. 85:705-717. https://doi.org/10.1016/j.bcp.2012.11.016.

Capuco, A. V., D. L. Wood, R. Baldwin, K. McLeod, and M. J. Paape. 2001. Mammary cell number, proliferation, and apoptosis during a bovine lactation: Relation to milk production and effect of bST. J. Dairy Sci. 84:2177-2187.

Chartoumpekis, D. V., P. G. Ziros, A. Zaravinos, R. P. Iskrenova, A. I. Psyrogiannis, V. E. Kyriazopoulou, G. P. Sykiotis, and I. G. Habeos. 2013. Hepatic gene expression profiling in Nrf2 knockout mice after long-term high-fat diet-induced obesity. Oxid. Med. Cell. Longev. 2013:340731. https://doi.org/10.1155/2013/340731.

Chorley, B. N., M. R. Campbell, X. Wang, M. Karaca, D. Sambandan, F. Bangura, P. Xue, J. Pi, S. R. Kleeberger, and D. A. Bell. 2012 Identification of novel NRF2-regulated genes by ChIP-Seq: influence on retinoid X receptor alpha. Nucleic Acids Res. 40:74167429. https://doi.org/10.1093/nar/gks409.

Colitti, M., C. J. Wilde, and B. Stefanon. 2004. Functional expression of bcl-2 protein family and AIF in bovine mammary tissue in early lactation. J. Dairy Res. 71:20-27.

Cuadrado, A., Z. Martin-Moldes, J. Ye, and I. Lastres-Becker. 2014. Transcription factors NRF2 and NF-kappaB are coordinated effectors of the Rho family, GTP-binding protein RAC1 during inflammation. J. Biol. Chem. 289:15244-15258. https://doi.org/10.1074/ jbc.M113.540633.

Dinkova-Kostova, A. T., J. W. Fahey, and P. Talalay. 2004. Chemical structures of inducers of nicotinamide quinone oxidoreductase 1 (NQO1). Methods Enzymol. 382:423-448.

Dinkova-Kostova, A. T., and P. Talalay. 2010. NAD(P)H:quinone acceptor oxidoreductase 1 (NQO1), a multifunctional antioxidant enzyme and exceptionally versatile cytoprotector. Arch. Biochem. Biophys. 501:116-123. https://doi.org/10.1016/j.abb.2010.03.019.

Du, Y., H. Zhang, X. Zhang, J. Lu, and A. Holmgren. 2013. Thioredoxin 1 is inactivated due to oxidation induced by peroxiredoxin under oxidative stress and reactivated by the glutaredoxin system. J. Biol. Chem. 288:32241-32247. https://doi.org/10.1074/jbc M113.495150.

Everts, R. E., M. R. Band, Z. L. Liu, C. G. Kumar, L. Liu, J. J. Loor, R. Oliveira, and H. A. Lewin. 2005. A 7872 cDNA microarray and its use in bovine functional genomics. Vet. Immunol. Immunopathol. 105:235-245.

Feng, J., X. Chen, X. Sun, F. Wang, and X. Sun. 2014. Expression of endoplasmic reticulum stress markers GRP78 and CHOP induced by oxidative stress in blue light-mediated damage of A2E-contain- ing retinal pigment epithelium cells. Ophthalmic Res. 52:224-233. https://doi.org/10.1159/000363387.

Gessner, D. K., G. Schlegel, J. Keller, F. J. Schwarz, R. Ringseis, and K. Eder. 2013. Expression of target genes of nuclear factor E2related factor 2 in the liver of dairy cows in the transition period and at different stages of lactation. J. Dairy Sci. 96:1038-1043. https://doi.org/10.3168/jds.2012-5967.

Glorieux, C., J. M. Sandoval, N. Dejeans, G. Ameye, H. A. Poirel, J. Verrax, and P. B. Calderon. 2016. Overexpression of NAD(P) $\mathrm{H}$ :quinone oxidoreductase 1 (NQO1) and genomic gain of the NQO1 locus modulates breast cancer cell sensitivity to quinones. Life Sci. 145:57-65. https://doi.org/10.1016/j.lfs.2015.12.017.

Gong, J., and M. Xiao. 2016. Selenium and antioxidant status in dairy cows at different stages of lactation. Biol. Trace Elem. Res. 171:89-93. https://doi.org/10.1007/s12011-015-0513-2.

Gumaa, K. A., A. L. Greenbaum, and P. McLean. 1973. Adaptive changes in satellite systems related to lipogenesis in rat and sheep mammary gland and in adipose tissue. Eur. J. Biochem. 34:188198

Hanczko, R., D. R. Fernandez, E. Doherty, Y. Qian, G. Vas, B. Niland, T. Telarico, A. Garba, S. Banerjee, F. A. Middleton, D. Barrett, M. Barcza, K. Banki, S. K. Landas, and A. Perl. 2009. Prevention of hepatocarcinogenesis and increased susceptibility to acetaminophen-induced liver failure in transaldolase-deficient mice by N-acetylcysteine. J. Clin. Invest. 119:1546-1557. https://doi .org/10.1172/JCI35722.

Hine, C. M., and J. R. Mitchell. 2012. NRF2 and the phase II response in acute stress resistance induced by dietary restriction. J. Clin. Exp. Pathol. S4:7329.

Huang, Y., W. Li, Z. Y. Su, and A. N. Kong. 2015. The complexity of the Nrf2 pathway: Beyond the antioxidant response. J. Nutr. Biochem. 26:1401-1413. https://doi.org/10.1016/j.jnutbio.2015.08 .001 .

Huang, Z. Z., C. Chen, Z. Zeng, H. Yang, J. Oh, L. Chen, and S. C. Lu. 2001. Mechanism and significance of increased glutathione level in human hepatocellular carcinoma and liver regeneration. FASEB J. 15:19-21.

Jaiswal, A. K. 2004. Nrf2 signaling in coordinated activation of antioxidant gene expression. Free Radic. Biol. Med. 36:1199-1207.

Jin, L., S. Yan, B. Shi, H. Bao, J. Gong, X. Guo, and J. Li. 2014. Effects of vitamin $\mathrm{A}$ on the milk performance, antioxidant functions and immune functions of dairy cows. Anim. Feed Sci. Technol. 192:15-23. https://doi.org/10.1016/j.anifeedsci.2014.03.003.

Jin, X., K. Wang, H. Liu, F. Hu, F. Zhao, and J. Liu. 2016a. Protection of bovine mammary epithelial cells from hydrogen peroxideinduced oxidative cell damage by resveratrol. Oxid. Med. Cell. Longev. 2016:2572175. https://doi.org/10.1155/2016/2572175.

Jin, X. L., K. Wang, L. Liu, H. Y. Liu, F. Q. Zhao, and J. X. Liu. 2016b. Nuclear factor-like factor 2-antioxidant response element signaling activation by tert-butylhydroquinone attenuates acute heat stress in bovine mammary epithelial cells. J. Dairy Sci. 99:9094-9103. https://doi.org/10.3168/jds.2016-11031.

Jomova, K., and M. Valko. 2011. Importance of iron chelation in free radical-induced oxidative stress and human disease. Curr. Pharm. Des. 17:3460-3473.

Kim, J. G., K. Back, H. Y. Lee, H. J. Lee, T. H. Phung, B. Grimm, and S. Jung. 2014. Increased expression of Fe-chelatase leads to increased metabolic flux into heme and confers protection against photodynamically induced oxidative stress. Plant Mol. Biol. 86:271-287. https://doi.org/10.1007/s11103-014-0228-3.

Kwak, M. K., N. Wakabayashi, and T. W. Kensler. 2004. Chemoprevention through the Keap1-Nrf2 signaling pathway by phase 2 enzyme inducers. Mutat. Res. 555:133-148.

Loor, J. J., M. Bionaz, and J. K. Drackley. 2013. Systems physiology in dairy cattle: nutritional genomics and beyond. Annu. Rev. Anim. Biosci. 1:365-392.

Lu, J., and A. Holmgren. 2014. The thioredoxin antioxidant system. Free Radic. Biol. Med. 66:75-87. https://doi.org/10.1016/j .freeradbiomed.2013.07.036. 
Lu, S. C. 2009. Regulation of glutathione synthesis. Mol. Aspects Med. 30:42-59. https://doi.org/10.1016/j.mam.2008.05.005.

Lu, S. C. 2013. Glutathione synthesis. Biochim. Biophys. Acta 1830:3143-3153. https://doi.org/10.1016/j.bbagen.2012.09.008.

Lykkesfeldt, J., and O. Svendsen. 2007. Oxidants and antioxidants in disease: Oxidative stress in farm animals. Vet. J. 173:502-511.

Mellenberger, R. W., D. E. Bauman, and D. R. Nelson. 1973. Metabolic adaptations during lactogenesis. Fatty acid and lactose synthesis in cow mammary tissue. Biochem. J. 136:741-748.

Menegon, S., A. Columbano, and S. Giordano. 2016. The dual roles of NRF2 in cancer. Trends Mol. Med. 22:578-593. https://doi.org/10 .1016/j.molmed.2016.05.002

Metcalfe, A. D., A. Gilmore, T. Klinowska, J. Oliver, A. J. Valentijn, R. Brown, A. Ross, G. MacGregor, J. A. Hickman, and C. H. Streuli. 1999. Developmental regulation of Bcl-2 family protein expression in the involuting mammary gland. J. Cell Sci. 112:17711783.

Moyes, K. M., J. K. Drackley, D. E. Morin, S. L. Rodriguez-Zas, R. E. Everts, H. A. Lewin, and J. J. Loor. 2010. Mammary gene expression profiles during an intramammary challenge reveal potential mechanisms linking negative energy balance with impaired immune response. Physiol. Genomics 41:161-170. https://doi.org/10 .1152 /physiolgenomics.00197.2009.

Niture, S. K., and A. K. Jaiswal. 2012. Nrf2 protein up-regulates antiapoptotic protein Bcl-2 and prevents cellular apoptosis. J. Biol. Chem. 287:9873-9886. https://doi.org/10.1074/jbc.M111.312694.

Nordberg, J., and E. S. Arner. 2001. Reactive oxygen species, antioxidants, and the mammalian thioredoxin system. Free Radic. Biol. Med. 31:1287-1312

Perl, A., R. Hanczko, T. Telarico, Z. Oaks, and S. Landas. 2011. Oxidative stress, inflammation and carcinogenesis are controlled through the pentose phosphate pathway by transaldolase. Trends Mol. Med. 17:395-403. https://doi.org/10.1016/j.molmed.2011.01 .014 .

Sadek, K., E. Saleh, and M. Ayoub. 2017. Selective, reliable blood and milk bio-markers for diagnosing clinical and subclinical bovine mastitis. Trop. Anim. Health Prod. 49:431-437. https://doi.org/ 10.1007/s11250-016-1190-7.

Schogor, A. L., M. F. Palin, G. T. Santos, C. Benchaar, P. Lacasse, and H. V. Petit. 2013. Mammary gene expression and activity of antioxidant enzymes and oxidative indicators in the blood, milk, mammary tissue and ruminal fluid of dairy cows fed flax meal. Br. J. Nutr. 110:1743-1750. https://doi.org/10.1017/ S0007114513001220.

Schorr, K., M. Li, S. Krajewski, J. C. Reed, and P. A. Furth. 1999. Bcl2 gene family and related proteins in mammary gland involution and breast cancer. J. Mammary Gland Biol. Neoplasia 4:153-164.

Siddiqui, W. A., A. Ahad, and H. Ahsan. 2015. The mystery of BCL2 family: Bcl-2 proteins and apoptosis: An update. Arch. Toxicol. 89:289-317. https://doi.org/10.1007/s00204-014-1448-7.

Sordillo, L. M., and S. L. Aitken. 2009. Impact of oxidative stress on the health and immune function of dairy cattle. Vet. Immunol. Immunopathol. 128:104-109. https://doi.org/10.1016/j.vetimm.2008 .10 .305 .

Sordillo, L. M., G. A. Contreras, and S. L. Aitken. 2009. Metabolic factors affecting the inflammatory response of periparturient dairy cows. Anim. Health Res. Rev. 10:53-63. https://doi.org/10.1017/ S1466252309990016.

Sun, Z., Z. Huang, and D. D. Zhang. 2009. Phosphorylation of Nrf2 at multiple sites by MAP kinases has a limited contribution in modulating the Nrf2-dependent antioxidant response. PLoS One 4:e6588. https://doi.org/10.1371/journal.pone.0006588.

Talukder, S., K. L. Kerrisk, G. Gabai, A. Fukutomi, and P. Celi. 2015. Changes in milk oxidative stress biomarkers in lactating dairy cows with ovulatory and an-ovulatory oestrous cycles. Anim. Reprod. Sci. 158:86-95. https://doi.org/10.1016/j.anireprosci.2015.05.004.

Valko, M., D. Leibfritz, J. Moncol, M. T. Cronin, M. Mazur, and J. Telser. 2007. Free radicals and antioxidants in normal physiological functions and human disease. Int. J. Biochem. Cell Biol. 39:44-84.

Vels, L., C. M. Rontved, M. Bjerring, and K. L. Ingvartsen. 2009. Cytokine and acute phase protein gene expression in repeated liver biopsies of dairy cows with a lipopolysaccharide-induced mastitis. J. Dairy Sci. 92:922-934. https://doi.org/10.3168/jds.2008-1209.

Wakabayashi, N., S. L. Slocum, J. J. Skoko, S. Shin, and T. W. Kensler. 2010. When NRF2 talks, who's listening? Antioxid. Redox Signal. 13:1649-1663. https://doi.org/10.1089/ars.2010.3216.

Wang, H., K. Liu, M. Geng, P. Gao, X. Wu, Y. Hai, Y. Li, Y. Li, L. Luo, J. D. Hayes, X. J. Wang, and X. Tang. 2013. RXRalpha inhibits the NRF2-ARE signaling pathway through a direct interaction with the Neh7 domain of NRF2. Cancer Res. 73:3097-3108. https://doi.org/10.1158/0008-5472.CAN-12-3386.

Wang, M., S. Moisá, M. J. Khan, J. Wang, D. Bu, and J. J. Loor. 2012. MicroRNA expression patterns in the bovine mammary gland are affected by stage of lactation. J. Dairy Sci. 95:6529-6535. https:// doi.org/10.3168/jds.2012-5748.

Wang, M., Z. Zhou, M. J. Khan, J. Gao, and J. J. Loor. 2015. Clock circadian regulator (CLOCK) gene network expression patterns in bovine adipose, liver, and mammary gland at 3 time points during the transition from pregnancy into lactation. J. Dairy Sci. 98:4601-4612. https://doi.org/10.3168/jds.2015-9430.

Wegiel, B., Z. Nemeth, M. Correa-Costa, A. C. Bulmer, and L. E. Otterbein. 2014. Heme oxygenase-1: a metabolic nike. Antioxid. Redox Signal. 20:1709-1722. https://doi.org/10.1089/ars.2013.5667.

Wu, J., H. Wang, and X. Tang. 2014. Rexinoid inhibits Nrf2-mediated transcription through retinoid X receptor alpha. Biochem. Biophys. Res. Commun. 452:554-559. https://doi.org/10.1016/j.bbrc .2014.08.111.

Xu, L., C. K. Glass, and M. G. Rosenfeld. 1999. Coactivator and corepressor complexes in nuclear receptor function. Curr. Opin. Genet. Dev. 9:140-147.

Yamane, Y., M. Furuichi, R. Song, N. T. Van, R. T. Mulcahy, T. Ishikawa, and M. T. Kuo. 1998. Expression of multidrug resistance protein/GS-X pump and gamma-glutamylcysteine synthetase genes is regulated by oxidative stress. J. Biol. Chem. 273:3107531085 .

Yang, L., M. Zahid, Y. Liao, E. G. Rogan, E. L. Cavalieri, N. E. Davidson, J. D. Yager, K. Visvanathan, J. D. Groopman, and T. W. Kensler. 2013. Reduced formation of depurinating estrogenDNA adducts by sulforaphane or KEAP1 disruption in human mammary epithelial MCF-10A cells. Carcinogenesis 34:2587-2592. https://doi.org/10.1093/carcin/bgt246.

Young, I. S., and J. V. Woodside. 2001. Antioxidants in health and disease. J. Clin. Pathol. 54:176-186.

Yu, G. M., H. Kubota, M. Okita, and T. Maeda. 2017. The antiinflammatory and antioxidant effects of melatonin on LPS-stimulated bovine mammary epithelial cells. PLoS One 12:e0178525. https://doi.org/10.1371/journal.pone.0178525.

Zhou, Z., T. A. Garrow, X. Dong, D. N. Luchini, and J. J. Loor. 2017. Hepatic activity and transcription of betaine-homocysteine methyltransferase, methionine synthase, and cystathionine synthase in periparturient dairy cows are altered to different extents by supply of methionine and choline. J. Nutr. 147:11-19. https://doi.org/10 $.3945 /$ jn.116.240234.

Zipper, L. M., and R. T. Mulcahy. 2003. Erk activation is required for Nrf2 nuclear localization during pyrrolidine dithiocarbamate induction of glutamate cysteine ligase modulatory gene expression in HepG2 cells. Toxicol. Sci. 73:124-134. https://doi.org/10.1093/ toxsci $/ \mathrm{kfg} 083$. 